\title{
NATURALEZA Y EXIGIBILIDAD DE LOS DERECHOS RECOGIDOS EN LOS ESTATUTOS DE AUTONOMÍA
}

Nature and enforceability of the rights proclaimed in the autonomous statutes

DOI: http://dx.doi.org/10.15304/dereito.26.2.4009

\author{
DANIEL JOVE ViLLARES \\ Investigador predoctoral de la Xunta de Galicia \\ Universidade da Coruña \\ d.jove.villares@udc.es
}

\section{Resumen}

En la primera década del siglo XXI algunas Comunidades Autónomas, en el marco de los procesos de reforma de sus Estatutos de Autonomía, incorporaron a su norma institucional básica declaraciones de derechos. Resulta determinante conocer cuál es la naturaleza jurídica de dichos derechos en la medida en que la subjetividad, de los mismos va a tener importantes consecuencias para el acervo jurídico de los ciudadanos. Así, en esta primera parte, se aborda el estudio de las cartas de derechos autonómicas, atendiendo para ello a cómo han sido formuladas amén del grado de concreción con que cada derecho ha sido enunciado. Se reserva para un segundo artículo el análisis de la exigibilidad que tales proclamaciones puedan tener, aspecto que será fundamental a la hora de valorar las consecuencias que para los ciudadanos han tenido las reformas estatutarias en lo que a protección de sus derechos se refiere.

Palabras clave: Derechos subjetivos, principios rectores, Estatuto de Autonomía, Derechos sociales, Comunidades Autónomas.

\section{Abstract}

In the first decade of the 21st century some of Autonomous Communities sought to reform their Autonomous Statutes; in the process of that reform, they incorporated declarations of rights. To better comprehension of the impact and results of the aforementioned declaration, one must understand the nature of these declarations; If there are rights which are deemed subjective then it follows that there will be consequence which impact the juridical heritage of the citizens of these Autonomies. In this first part of our study we will undertake the discussion of the rights included in the Autonomous Charters. To that end, we will focus our attention on the articulation of their precepts as well as the degree of accuracy and precision with which each right has been formulated. In a subsequent article, consideration will be given to the enforceability of these proclamations, which are considered crucial to evaluate the

Recibido: 06/03/2017. Aceptado: 12/04/2017. 
potentially deleterious consequences to the protection of the rights of citizens.

Key words: Subjective rights, guiding principles, Autonomous Statutes, Social rights, Autonomous Communities.

\section{SUMARIO}

1. INTRODUCCIÓN.- 2. LOS ESTATUTOS DE AUTONOMÍA COMO FUENTE VÁLIDA PARA REGULAR DERECHOS.- 2.1. Introducción.- 2.2. La viabilidad constitucional de las declaraciones de derechos.- 2.3. Límites de las declaraciones de derechos.- 3.NATURALEZA DE LOS DERECHOS ESTATUTARIOS.- 3.1. Derechos subjetivos y principios rectores.- 3.2. Una amplia gama de principios rectores.- 3.3. No todos son principios, hay auténticos derechos subjetivos.- 4. CONCLUSIÓN.- 5. BIBLIOGRAFÍA.

\section{SUMMARY}

1. INTRODUCTION.- 2. THE STATUTES OF AUTONOMY AS A VALID SOURCE TO REGULATE RIGHTS.- 2.1. Introduction.- 2.2. The constitutional viability of the declarations of rights.- 2.3. Limits of the declarations of rights.- 3. NATURE OF STATUTORY RIGHTS.- 3.1. Subjective rights and guiding principles.- 3.2. A wide range of guiding principles.- 3.3. Not all are principles, but also genuine subjective rights.4. CONCLUSION.- 5. BIBLIOGRAPHY.

\section{INTRODUCCIÓN ${ }^{1}$}

En los primeros años del siglo XXI algunas Comunidades Autónomas (en adelante CCAA) iniciaron importantes procesos de reforma de sus normas de cabecera ${ }^{2}$. No se trataba de meras reformas cosméticas sino de reformas de gran calado que buscaban apuntalar las conquistas de poder que los territorios habían alcanzado. Junto a tal objetivo se pretendía dar un nuevo impulso al proceso de descentralización al configurar unos Estatutos que, en sus formas y, en cierto modo, en su contenido les asemejaban a una Constitución. En este sentido, la inclusión de las declaraciones de derechos jugó un papel muy destacado a la hora de dotar a los Textos autonómicos del empaque y fuerza propios de cualquier Norma Fundamental. Y es que, como proclama el artículo 16 de la Declaración de Derechos del Hombre y del Ciudadano: «Toda sociedad en la cual no esté establecida la garantía de los derechos, ni determinada la separación de poderes, carece de Constitución». Por lo tanto, y aunque

\footnotetext{
1 Abreviaturas utilizadas en el estudio doctrinal: Comunidades Autónomas (CCAA); Constitución Española (CE); LO (Ley Orgánica); Sentencia Tribunal Constitucional (STC); Tribunal Constitucional (TC).

${ }^{2}$ Andalucía (2006), Aragón (2007), Castilla y León (2007), Cataluña (2006), Comunidad Valenciana (2006), Extremadura (2011), Islas Baleares (2007). También ha sido reformada la Ley Orgánica de reintegración y amejoramiento del Régimen Foral de Navarra por la Ley Orgánica 7/2010, de 27 de octubre, reforma que si bien no tiene el calado de las demás en lo que respecta a los derechos estatutarios si tiene su interés por la incorporación a la Ley Orgánica de amejoramiento de un artículo 18 ter en el que se regula la institución del Defensor del Pueblo de Navarra.
} 
su naturaleza de norma bifronte y subordinada a la Constitución no ha cambiado, no puede negarse que las Cartas de derechos estatutarias venían a reforzar sobremanera la posición de los Estatutos como Norma superior del ordenamiento autonómico. Al mismo tiempo, las CCAA se erigían como agentes de primer orden en la satisfacción y garantía de los derechos de sus ciudadanos.

Con unas consecuencias de tal magnitud no resulta extraño que se cuestionara la constitucionalidad de las Declaraciones de derechos. Sin embargo, siendo las razones que se arguyeron razonables, lo cierto es que, como aquí constataremos, la facultad de las CCAA para recoger en sus Estatutos tales proclamaciones es perfectamente constitucional, y así lo ha corroborado el Alto Tribunal español. Cuestión diferente será la naturaleza y exigibilidad de tales derechos.

Esos dos aspectos, naturaleza y exigibilidad, son los grandes ejes de este trabajo y, la clarificación de los mismos, el objetivo que se persigue. En tarea tan relevante resulta fundamental tomar en consideración un aspecto esencial: que la amplísima mayoría de los bienes jurídicos que los Estatutos reformados vienen a proteger son de carácter prestacional. La preeminencia de esta cuestión es de tal magnitud que viene a dotar a las reformas estatutarias de una finalidad: salvaguardar jurídicamente los derechos sociales dándoles una nueva configuración que los convirtiera en auténticos derechos y dejando de ser meras aspiraciones.

No cabe duda que uno de los grandes retos a los que se enfrentan las actuales sociedades es, precisamente, hacer posible un Estado social en una época en que las necesidades y apuros económicos han hecho tambalear la existencia del mismo. En ese sentido, revestir a los derechos sociales de una protección jurídica superior es toda una declaración de intenciones $y$, a la vez, una apuesta por un modelo de sociedad y por consolidar el Estado del bienestar.

Sin embargo, siendo las intenciones de los estatuyentes una orientación importante, lo realmente relevante es determinar si las proclamaciones de derechos por ellos configuradas cuentan con la fuerza jurídica suficiente para propiciar una mejora en la posición jurídica de los ciudadanos. Por eso resulta vital clarificar cuál es la naturaleza y exigibilidad de estos derechos. Para lograr dar respuesta a esos dos interrogantes se ha atendido especialmente a la propia formulación de los preceptos, a cómo han sido configurados por el estatuyente y no tanto a la veste de la que han sido revestidos. Con tal análisis se busca determinar cuál es la naturaleza de las Cartas de derechos autonómicas y, a partir de esa naturaleza, establecer el nivel de exigibilidad de que las mismas están dotadas. Porque, volviendo al precepto de la Declaración de Derechos del Hombre y del Ciudadano, lo determinante es la «garantía de los derechos» y es que, de no contar con un nivel de exigibilidad apropiado, estaríamos ante proclamas de escasa fuerza jurídica lo que solo generaría frustración en los ciudadanos.

Por todo ello considero que clarificar la naturaleza y exigibilidad de las declaraciones estatutarias resulta determinante para conocer cuál es la 
situación de los derechos en España. No solo para saber qué podemos esperar y exigir de los poderes públicos sino también para identificar donde es posible mejorar el nivel de protección de los derechos; objetivo que puede verse frustrado por proclamaciones que generen una apariencia de protección que en la realidad no ofrezcan. Si los nuevos Estatutos provocan tal situación, o no, es una de las respuestas que con este trabajo buscamos proporcionar.

\section{LOS ESTATUTOS DE AUTONOMÍA COMO FUENTE VÁLIDA PARA REGULAR DERECHOS}

\subsection{Introducción}

La determinación del alcance de la protección que las declaraciones estatutarias de derechos proporcionan requiere, como presupuesto previo sin cuya resolución este trabajo no tendría sentido, dar respuesta a la pregunta de si ¿pueden los Estatutos de Autonomía declarar derechos, deberes y principios? ${ }^{3}$ Esa pregunta da título a un trabajo de DÍEZPICAZO y, en torno a esa cuestión, se suscitó todo un debate doctrinal. Debate del que CAAMAÑO fue otro de los protagonistas, precisamente por dar réplica a las dudas planteadas en torno a la capacidad de los Estatutos para albergar declaraciones de derechos, señalando que sí pueden ${ }^{4}$, respuesta afirmativa que compartimos. Es por ello que en este trabajo se afirma la viabilidad de las declaraciones de derechos. Lo contrario nos llevaría a plantear un trabajo diferente, en el que se tratara de determinar, no la efectividad de los derechos estatutarios, sino el modo de garantizar su existencia.

Aun siendo consciente de que la cuestión de si los Estatutos de Autonomía pueden contener cartas de derechos ha sido profusamente debatida por nuestra doctrina y resuelta por el Tribunal Constitucional en la sentencia sobre el Estatuto de la Comunidad Valenciana, 247/2007, de 12 de diciembre, y reafirmada con la STC 31/2010, de 28 de junio, relativa al Estatuto de Cataluña, considero conveniente traer aquí los argumentos que, desde mi punto de vista, sustentan el dar una contestación positiva. La razón principal para dicha respuesta, es que es constitucionalmente posible, no hay en nuestra Constitución impedimentos formales ni hay, en la práctica, motivos sustantivos que puedan impedir al estatuyente incorporar, si lo estima oportuno, conveniente y necesario, declaraciones de derechos a su norma institucional básica ${ }^{5}$.

\subsection{La viabilidad constitucional de las declaraciones de derechos}

\footnotetext{
${ }^{3}$ L. M. DÍEZ-PICAZO, "¿Pueden los estatutos de autonomía declarar derechos, deberes y principios?", Revista Española de Derecho Constitucional, No 78, septiembre-diciembre, 2006, pp. 63-75.

${ }^{4}$ F. CAAMAÑO, "Sí, pueden (Declaraciones de derechos y Estatutos de Autonomía)", Revista Española Derecho Constitucional, No 79, enero-abril, 2007, pp. 33-46.

5 La naturaleza bifronte de los Estatutos de Autonomía derivada de su condición de norma institucional básica de las CCAA y, a la vez, LO del Estado ha sido reconocida por el Tribunal Constitucional entre otras en las SSTC: 76/1983, 61/1997 o la 132/2012.
} 
Si se hiciera una interpretación literal del artículo 147.2 de la Constitución nos encontraríamos con que la inclusión de una carta de derechos, o cualquier otra previsión que desbordara los preceptos en él previstos, sería inconstitucional. Pero, en lo que se refiere a la configuración territorial del poder, sabemos que para comprender nuestra realidad territorial no basta con la lectura de nuestra Norma Fundamental ${ }^{6}$ sino que resulta indispensable estar a lo que disponen los Estatutos y a la interpretación que el TC realiza.

El TC, ya desde los años 80, venía señalando que el artículo 147.2 recoge «la determinación del contenido mínimo de los Estatutos» (STC $89 / 1984$, de 28 de septiembre, FJ. 4). Por tanto, existe acuerdo respecto a que lo dispuesto en el artículo 147.2 es solo un mínimo necesario que los Estatutos de autonomía deben contener ${ }^{7}$. Junto a ese contenido mínimo estarían una serie de preceptos de la CE que atribuyen a los Estatutos la posibilidad de regular determinados aspectos específicos ${ }^{8}$. De hecho, el debate doctrinal se centraba, hasta los estatutos de nueva generación, en determinar «si aquellas materias cuya regulación les es atribuida [a los Estatutos] por la Constitución en preceptos distintos del art. 147.2 forman parte de su contenido necesario, o son simplemente un contenido posible»?.

Sin embargo, autores como CARRILLO han planteado la hipótesis de una extensión de ese contenido posible de los Estatutos de Autonomía ${ }^{10}$. Es decir, lo que se plantea, no es ya si los estatutos pueden regular aspectos constitucionalmente previstos, sino si pueden extenderse a aspectos no previstos expresamente en la CE. Por lo que el debate se eleva hasta alcanzar el punto que aquí buscamos clarificar, que no es otro que determinar si los Estatutos pueden tener un contenido dogmático de

\footnotetext{
${ }^{6}$ Ya tempranamente (1981) lo puso de manifiesto, de un modo brillante, Pedro Cruz Villalón en su conocida obra: La curiosidad del jurista persa, puede encontrarse esta obra junto con otros estudios de este autor en, P. CRUZ VILLALÓN, La curiosidad del jurista persa, y otros estudios sobre la Constitución, Centro de Estudios Políticos y Constitucionales, 2a Edición, Madrid, 2006.

7 Cfr. R. CANOSA USERA, "La declaración de derechos en los nuevos Estatutos de Autonomía", Teoría y Realidad Constitucional, No 20, 2007, pp. 59-115.

${ }^{8}$ L. M. DÍEZ-PICAZO identifica los siguientes preceptos: 69.5, 145.2, 152 y el 156.2. A Ios que CANOSA USERA añade: 3.2, 4.2, 133.2. En R. CANOSA USERA, "La declaración de...", op. cit., p. 69.

El artículo 3.2 es el mejor ejemplo de un contenido que los Estatutos de Autonomía pueden regular, o no, dependiendo de la CA y de si sus características le posibilitan el plantearse siquiera su articulación. Pero, además, es una muestra paradigmática de que el asunto de los derechos no es una materia completamente nueva para los Estatutos, sino que ya los primeros Estatutos regulaban algunos derechos, muy pocos, sin orden sistemático y en aspectos muy particulares (v. gr. los lingüísticos), pero derechos a fin de cuentas.

${ }^{9}$ L. M. DÍEZ-PICAZO, "¿Pueden los estatutos..., op. cit., p. 66.

10 M. CARRILLO, "La declaración de derechos en el nuevo Estatuto de Autonomía de Cataluña: expresión de autogobierno y límite a los poderes públicos", en Derechos, deberes y principios en el nuevo Estatuto de Autonomía de Cataluña, Centro de Estudios Políticos y Constitucionales, Madrid, 2006, p. 65 y ss. También se plantea esta idea en el Dictamen 269/2005, del Consejo Consultivo de Cataluña.
} 
la magnitud del que se han dotado con las reformas de la primera década del siglo XXI.

Para poder dar una respuesta afirmativa a tal interrogante debemos enfrentarnos a la cuestión de hasta dónde alcanzan los límites constitucionales al contenido que los Estatutos pueden regular. Si entendiéramos que los Estatutos solo pueden regular lo que expresamente prevé la CE y nada más ${ }^{11}$, entonces habría de concluirse que las declaraciones de derechos estatutarias no son constitucionales y solo quedaría declarar su inconstitucionalidad. Pero no creo que sea así, no creo que deba hacerse una interpretación tan literal y restrictiva de lo que es constitucionalmente posible que los Estatutos regulen utilizando como único argumento que no está expresamente previsto. Debe tenerse en cuenta que la CE apenas si esboza las líneas generales que permitirían construir a través de los pactos autonómicos y, sobre todo, con la labor del TC nuestro modelo territorial ${ }^{12}$. Nuestra opinión, como se ha ido insinuando, es coincidente con la interpretación que la mayoría de la doctrina suscribe y que el TC ha venido a validar al considerar constitucionales las declaraciones de derechos. Con esa idea como punto de partida, se procederá a dar las razones por las que apartarse de una interpretación que acota tanto el contenido de los Estatutos es, no solo constitucionalmente posible, sino el modo más correcto de interpretar nuestro actual sistema de descentralización política.

La primera de las razones es de índole práctica, la CE ha de interpretarse respetando su contenido, sí, pero también tomando en consideración la realidad a la que se aplica porque desconocerla podría llevar a resoluciones cuya efectividad fuera cuestionable. De ahí que entienda que para realizar una interpretación correcta del problema que nos atañe lo primero que debe tomarse en consideración es el actual grado de descentralización territorial del poder sobre el que operan la CE y los Estatutos. El propio TC pone de manifiesto que esta debe ser la línea a seguir al señalar que «dada la apertura y flexibilidad del modelo territorial, serían constitucionalmente admisibles Estatutos de Autonomía dotados de un contenido más amplio que el que resulta del mínimo necesario del art. 147.2 CE» ${ }^{13}$.

\footnotetext{
${ }^{11}$ Además de L. M. DÍEZ-PICAZO, también suscribe esta idea J. GARCÍA TORRES, "Los derechos estatutarios en la propuesta catalana de reforma", en El Estado autonómico. Actas de las XI Jornadas de la Asociación de Letrados del Tribunal Constitucional, Centro de Estudios Políticos y Constitucionales, Madrid, 2006, p. 67.

12 Llegando incluso a calificarse por ARAGÓN REYES de "Estado jurisdiccional autonómico" en M. ARAGÓN REYES, "¿Estado jurisdiccional autonómico?", Revista Vasca de Administración Pública, No 16, septiembre-diciembre, 1986, pp. 7-12.

Sobre la construcción jurisdiccional del Estado autonómico vid. también: E. AJA FERNÁNDEZ, Estado Autonómico y reforma federal, Alianza editorial Madrid, 2014; S. A. ROURA GÓMEZ, Federalismo y Justicia constitucional en la Constitución española de 1978, Biblioteca Nueva, Madrid, 2003; E. AJA FERNÁNDEZ y P. PÉREZ TREMPS, "Tribunal Constitucional y organización territorial del Estado Autonómico", en VV.AA (E. ESPÍN TEMPLADO y F. DÍAZ REVORIO, coords.), La Justicia Constitucional en el Estado democrático, Cortes de Castilla-La Mancha/Tirant lo Blanch, Valencia, 2000.

13 STC 31/2010, FJ. 5.
} 
Centrándonos en el problema concreto, lo cierto es que, hasta la STC 247/2007, el TC no se había pronunciado específicamente sobre cuál era el contenido posible de un Estatuto de Autonomía ${ }^{14}$. Y cuando se le presenta la ocasión se enfrenta a la cuestión utilizando una interpretación sistemática de la $\mathrm{CE}$, poniendo el apartado 2 del artículo 147 en relación con el apartado 1 del mismo. Este último, será el precepto que servirá como fundamento para el análisis del contenido de los Estatutos de Autonomía.

El mencionado apartado 1 define la naturaleza de los Estatutos, y lo hace en los siguientes términos: «Dentro de los términos de la presente Constitución, los Estatutos serán la norma institucional básica de cada CCAA y el Estado los reconocerá y amparará como parte integrante de su ordenamiento jurídico». Es decir, el Estatuto de Autonomía no es una norma más del ordenamiento. No es una Ley Orgánica sin más ${ }^{15}$, sino que su naturaleza bifronte y su objeto le sitúan en una posición especial en el ordenamiento. Su condición de norma superior dentro de su ámbito territorial, solo subordinada a la $\mathrm{CE}^{16}$, y encargada de hacer efectivo el derecho a la autonomía del artículo 2 de la $\mathrm{CE}$, la convierten en una norma que «puede tender a ser, válidamente, una norma autosuficiente» ${ }^{17}$, aunque siempre respetando el marco constitucional.

Tomando en cuenta la naturaleza de los Estatutos de Autonomía resulta razonable que entre las materias que pueden regular se encuentren los derechos. Relacionado con esto, APARICIO y BARCELÓ, consideran la ausencia de un límite expreso en la CE como uno de los aspectos habilitantes para la regulación de derechos por los Estatutos, y es que «si se puede afirmar que en la Constitución no existe prohibición alguna de que los Estatutos contengan normas que adscriban expectativas a una generalidad de sujetos, la conclusión no puede ser otra que la de que los Estatutos son instrumentos jurídicos hábiles para la creación de derechos ${ }^{18}$. Aunque tal afirmación pueda reputarse correcta se ha de hacer tomando en cuenta que existen límites a las capacidades del estatuyente, límites que más adelante señalaremos, pues antes conviene traer a colación otros argumentos que vendrán a complementar la constitucionalidad de las declaraciones de derechos.

El más destacado de esos argumentos quizá sea el ofrecido por la propia STC $247 / 2007$ al atribuir un papel decisivo al principio dispositivo como vehículo a través del cual se ha ido configurando la autonomía de cada CA (Comunidad Autónoma). De hecho, configura el Alto Tribunal al

\footnotetext{
14 STC 247/2007, FJ. 11.

15 «Son leyes orgánicas...aunque sean especialmente cualificadas, y...radicalmente distintas de las demás», en M. ARAGÓN REYES, Estudios de Derecho Constitucional, Centro de Estudios Políticos y Constitucionales, Madrid, 2013, p. 840.

${ }^{16}$ STC 76/1983, de 5 de agosto, de la LOAPA. FJ.4

17 J. A. SANTAMARÍA PASTOR, Fundamentos de Derecho Administrativo, Editorial Centro de Estudios Ramón Areces, Madrid, 1988, p.588.

18 M. A. APARICIO PÉREZ y M. BARCELÓ I SERRAMELERA, "Los derechos públicos estatutarios", en VV.AA (M. A. APARCIO PÉREZ, ed.), Derechos y principios rectores en los Estatutos de Autonomía, Atelier, Barcelona, 2008, p. 19.
} 
principio dispositivo como elemento justificador para «considerar que el contenido legítimo de los Estatutos no se restringe a lo literalmente previsto en el art. 147.2 y 3 CE y restantes previsiones constitucionales expresas» ${ }^{19}$.

La razón de ser de este argumento no es otra que la propia naturaleza del principio dispositivo. Se trata de un elemento fundamental en la construcción del Estado autonómico al posibilitar que cada uno de los territorios optara, dentro de las posibilidades que la CE le ofrecía, por configurar un marco institucional y competencial propio adecuado a las necesidades que su autonomía reclamaba ${ }^{20}$. Sin embargo, como pone de manifiesto el TC al traer a colación la configuración institucional del poder por las CCAA, éstas han regulado estatutariamente órganos no previstos constitucionalmente pero eso no los convierte en inconstitucionales, aun al contrario, lo que conllevan es una realización efectiva de la capacidad de autoorganización de las CCAA y, por tanto, de la autonomía política de éstas. Razón por la cual, entre los aspectos que los Estatutos pueden regular se encuentran las relaciones de los poderes e instituciones autonómicos con sus ciudadanos ${ }^{21}$.

Muy vinculada a esa capacidad de los Estatutos para ordenar las relaciones entre los poderes públicos y los ciudadanos está la idea de que las declaraciones de derechos estatutarias operan como límite al poder y suponen una garantía para los ciudadanos, en la medida en que los poderes públicos también están sometidos a los Estatutos como parte del ordenamiento jurídico $(9.1 \mathrm{CE})$. Esta ha sido una de las ideas que la doctrina ha planteado como argumento relevante para justificar la constitucionalidad de las declaraciones de derechos, ya que «hay pocas cuestiones más propias de una norma institucional básica que el reconocimiento de derechos de sus miembros frente a sus órganos de autogobierno»22.

CAAMAÑO, que comparte la idea de los derechos como límite al poder, aporta un nuevo argumento que, a mi entender, termina por romper cualquier duda que pueda suscitarse respecto a una posible reserva constitucional que pudiera existir que hiciera que la regulación de derechos no pudiera ser abordada por los Estatutos. Su argumento parte de la premisa de que «no existen unos derechos reservados a la Constitución». Que la Constitución regule derechos, según este autor, no supone que la regulación de los derechos quede vedada a otro tipo de fuentes, sino que tiene como consecuencia que los derechos contemplados en la CE van a gozar «de un estatuto jurídico especial que les permite poseer la fuerza jurídica de la Constitución».

\footnotetext{
${ }^{19}$ STC 247/2007, FJ. 12.

20 Vid. J. RUIPÉREZ ALAMILLO, La Constitución del Estado de las Autonomías, Biblioteca Nueva Madrid, 2003.

${ }^{21}$ STC 247/2007, FJ. 12.

22 C. VIVER I PI SUNYER, "L' Estatut de 2006", Activitat Parlamentaria, No 10, 2006, p. 42.
} 
Este punto de vista se ve reforzado por dos hechos no menos contrastables, las CCAA ya regulaban algunos derechos en sus Estatutos ${ }^{23}$ y, la mayoría de ellas, contaban con legislación sobre muchos de los aspectos contenidos en las cartas de derechos que tanta polémica han generado. Aunque, como señala AJA, «no era razonable que no pudieran figurar en el Estatuto. [Ya que] Esencialmente, se trata de elevar el rango normativo de su reconocimiento para reforzar su aplicación» ${ }^{24}$. A pesar de lo sensato de esta afirmación, la elevación a rango estatutario de los derechos autonómicos sí suscita ciertas controversias que conviene aclarar. Y es que puede cuestionarse, como han señalado algunos autores, la restricción que supone a la capacidad de actuación futura del legislador autonómico ${ }^{25}$.

Sin embargo, a los argumentos que se puedan esgrimir contra la elevación a nivel estatutario se pueden oponer otros no menos válidos. De un lado, el carácter democrático de los Estatutos es incuestionable en la medida en que se trata de una norma fruto de la concurrencia de dos voluntades democráticas que, en ocasiones, cuenta, además, con el refrendo de una votación del pueblo de la CA. Y, sobre todo, porque afirmar que la elevación a nivel estatutario de las declaraciones de derechos pueda condicionar la labor del legislador autonómico resulta una aseveración que desconoce la realidad de las propias cartas de derechos autonómicas. $Y$ es que, en muchas ocasiones, son los propios preceptos estatutarios los que llaman al legislador para que los desarrolle. Se trata, además, de declaraciones que, tal y como han sido interpretadas por el TC, contienen, principalmente, «mandatos al legislador y restantes poderes públicos autonómicos, imponiéndoles prescripciones que son vinculantes para los mismos con independencia de la veste de que se revistan ${ }^{26}$.

Como puede comprobarse son muchas, y de gran calado, las razones que justifican que los Estatutos puedan contener declaraciones de derechos. Hasta el momento considero que con los argumentos que aquí se han recogido queda más que demostrado que no existe una limitación

\footnotetext{
${ }^{23}$ El ejemplo más notable de que las CCAA ya regulaban derechos es la regulación de los derechos lingüísticos derivada del artículo 3.2 de la Constitución.

${ }^{24}$ E. AJA, Estado autonómico y reforma federal, Alianza editorial, Madrid, 2014, p. 153. En el mismo sentido se pronuncia CAAMAÑo que señala lo paradójico que se dé por válido un derecho por ley autonómica y que esa misma regulación se le prive de validez si se regula a nivel estatutario, en CAAMAÑO, F. (2007): "Sí, pueden..., op. cit., p. 35.

25 V. FERRERES COMELLA, "Derechos, deberes y principios en el nuevo Estatuto de Autonomía de Cataluña", en Derechos, deberes y principios en el nuevo Estatuto de Autonomía de Cataluña, Centro de Estudios Políticos y Constitucionales, Madrid, 2006, p. 17 y ss. Incide en que al limitar la capacidad del legislador autonómico también se está limitando la capacidad de autogobierno de las propias CCAA.

DÍEZ-PICAZO, plantea también este argumento pero incidiendo en que tal elevación y la consiguiente limitación de la capacidad del legislador autonómico supondría una afectación del sistema democrático pues conllevaría privar «a los ciudadanos por vía estatutaria de algo que tenían por vía constitucional». En L. M. DIEZ-PICAZO, "¿Pueden los estatutos..., op. cit., p. 71.
}

${ }^{26}$ STC 247/2007. FJ. 15. 
formal en nuestra Constitución que haga imposible la regulación de derechos en los Estatutos. Pero queda un último escollo antes de proceder a determinar los límites de lo que las declaraciones estatutarias pueden abarcar: dar respuesta a las dudas que, legítimamente, se planteen desde un punto de vista sustantivo. Las alegaciones que puedan hacerse desde este punto de vista han de ser resueltas sin atisbo de duda, pues con ello quedaría resuelta, de un modo incuestionable, la constitucionalidad de las declaraciones estatutarias de derechos.

De las posibles alegaciones que desde este punto de vista pudieran hacerse considero que quizá la más relevante es la formulada por DÍEZPICAZO cuando, partiendo de la idea de que los Estatutos de Autonomía, y sus reformas, han de ser aprobadas por el parlamento estatal, plantea que en la medida en que las declaraciones de derechos pueden contener previsiones no necesariamente iguales, el legislador estatal podría convertirse en un «legislador esquizofrénico» ${ }^{27}$ capaz de aprobar una cosa y su contraria en función de la $\mathrm{CA}^{28}$.

Ese argumento choca de frente con la realidad que se desprende de las cartas de derechos en las que hay «cierta uniformidad y no se advierten entre ellos graves contradicciones en materia de derechos» ${ }^{29}$. Aunque no podría ser de otro modo si se tiene en cuenta que la CE es un límite y una guía para las declaraciones estatutarias. Esa uniformidad mínima viene garantizada por el artículo 149.1.1 CE y a través de legislación básica estatal que permite asegurar que en todo el territorio nacional exista un mínimo de garantías. Con todo ello se logra evitar que la esquizofrenia pueda apoderarse del legislador nacional.

\subsection{Límites de las declaraciones de derechos}

Una vez establecido que los Estatutos de Autonomía pueden contener declaraciones de derechos conviene determinar hasta dónde alcanza la capacidad que estamos reconociendo. Los límites que encuentra el estatuyente a la hora de elaborar su tabla de derechos serían: la reserva de Ley Orgánica en la regulación de los Derechos fundamentales y de las Libertades públicas (artículos 15-29 CE) tal como exige el artículo 81.1 CE; el respeto al artículo 149.1.1 y, como quizá gran novedad, el circunscribirse a las competencias atribuidas, en el sentido de que no podrán regularse derechos que conlleven la atribución de nuevas competencias para las CCAA ${ }^{30}$.

${ }^{27}$ L. M. DIEZ-PICAZO, "¿Pueden los estatutos..., op. cit., p. 72 y ss.

${ }^{28}$ Situación que por otra parte ya se ha dado en etapas pretéritas de la descentralización autonómica sin que se temiera por la salud mental del legislador estatal; baste recordar que las competencias en sanidad y educación no estuvieron transferidas a todas las CCAA hasta la Ley Orgánica 9/1992, de 23 de diciembre, de transferencia de competencias a Comunidades Autónomas que accedieron a la autonomía por la vía del artículo 143 de la Constitución, transferencias que se irían materializando a lo largo de esa década.

${ }^{29}$ R. CANOSA USERA, "La declaración de..., op. cit., p. 81.

${ }^{30} \mathrm{Si}$ bien es cierto que se trata de una novedad relativa, pues la Carta de los Derechos Fundamentales de la UE contiene en su artículo 51 una previsión idéntica pero referida al ámbito europeo, obviamente. 
Por lo que respecta a la reserva de Ley Orgánica, su contenido y alcance ha sido definido por el TC. De una parte, al señalar que no se trata de un precepto atributivo de competencias ${ }^{31}$. Y, a la vez, incidiendo en que se trata de una norma con un cometido específico: regular las condiciones básicas de aquellas materias para las que ha sido constitucionalmente reservada, entre las que se cuentan los derechos fundamentales. La clave para compaginar esta reserva de Ley se encuentra precisamente, en el último aspecto mencionado, esto es, en que la Ley Orgánica regula el contenido mínimo básico y, a la vez, deja cierto margen para el desarrollo de dichos derechos. Desarrollo que, en este caso, habrían hecho los Estatutos ${ }^{32}$.

Por otra parte, aunque relacionado con lo anterior, debe recordarse que el artículo 149.1.1 CE atribuye al Estado la competencia sobre la legislación básica en materia de derechos. Tomando como referencia la interpretación que de este precepto hace el TC, se hace patente su condición de límite a las cartas de derechos estatutarias al atribuir al Estado capacidad para articular las condiciones básicas de un determinado derecho cuando «fuere aconsejable para evitar una excesiva diversidad que pudiera menoscabar la entidad sustancial del derecho de que se trate» 33 .

Por lo que respecta a la exigencia de igualdad del artículo 139.1 CE no debe entenderse como uniformidad, tal y como el TC ha venido señalando en su jurisprudencia. Se trata de un límite relativo, «susceptible de modulaciones diferenciadas en mayor o menor grado en las CCAA, según el tipo de derecho que se trate y el reparto competencial en la materia implicada» ${ }^{34}$. La funcionalidad de este precepto a la hora de elaborar una declaración de derechos resultará más clara si lo ponemos en relación con la distribución de competencias y con los dos artículos anteriores, que se erigen en medios para llevar a efecto la exigencia de igualdad.

La distribución de competencias es el último límite que han de respetar las declaraciones de derechos. Se trata de un límite que la mayoría de los estatutos de segunda generación han sabido plasmar en sus Textos. Sirva como ejemplo paradigmático el artículo 37.4 del Estatuto de Autonomía de Cataluña: «Los derechos y principios del presente Título no supondrán una alteración del régimen de distribución de competencias, ni la creación de títulos competenciales nuevos o la modificación de los ya existentes. Ninguna de las disposiciones de este Título puede ser desarrollada, aplicada o interpretada de forma que reduzca o limite los derechos fundamentales reconocidos por la

\footnotetext{
${ }^{31}$ STC 137/1986, de 6 de noviembre.

32 Sirva como ejemplo el caso de la educación, que como derecho fundamental, está reservado a la LO pero a la vez queda margen para que las CCAA puedan realizar un desarrollo normativo en el marco de sus competencias.

${ }^{33}$ STC 247/2007, FJ. 17.

34 STC 247/2007, FJ.13. Pero se trata de un asunto que la jurisprudencia ha trata desde sus inicios: SSTC: $37 / 1981$, de 16 de noviembre; 173/1998, de 23 de julio y 37/2002, de 14 de febrero.
} 
Constitución y por los tratados y convenios internacionales ratificados por España» ${ }^{35}$.

En definitiva, las declaraciones de derechos no podrán suponer la asunción de nuevas competencias por las CCAA. Y esto es así, aun cuando el propio Estatuto no haga una previsión expresa como la aquí citada, debido a que «las relaciones del Estado, titular de la soberanía, con las CCAA, dotadas de autonomía política, se sustentan en la fijación de esferas de competencia indisponibles e irrenunciables por imperativo constitucional» ${ }^{36}$. De esta afirmación se deriva otra, los Estatutos solo podrán regular derechos en aquellas materias en que tengan asumidas competencias, y lo harán además respetando los límites fijados por la CE.

\section{NATURALEZA DE LOS DERECHOS ESTATUTARIOS}

\subsection{Derechos subjetivos y principios rectores}

Los Estatutos de Autonomía pueden contener tablas de derechos, como se ha acreditado, sin embargo, la regulación que los distintos textos autonómicos dan a esas declaraciones distan de seguir «un modelo predeterminado» ${ }^{37}$. Si se hace un análisis comparado de los Estatutos aprobados en la primera década del 2000 puede comprobarse que los legisladores estatutarios afrontaron esta cuestión con distinto grado de intensidad. En una panorámica general podemos encontramos con Estatutos que apenas si hacen una breve mención a los derechos y principios rectores, sin llegar a hacer nuevas aportaciones y, básicamente, remitiéndose a los preceptos constitucionales ${ }^{38}$. Pero también veremos Estatutos en los que se realiza una ordenación sistemática de los bienes jurídicos de sus ciudadanos, distinguiendo entre derechos y principios, aunque con distinto grado de detalle y profundidad dependiendo de cada CA.

Para poner rostro a las afirmaciones del párrafo anterior, lo que venimos a afirmar es que no es lo mismo el contenido formal y material de los Estatutos catalán, andaluz y castellano-leonés, mucho más prolijos y ordenados (aun habiendo matices destacables en cuanto a la profundidad y grado de detalle), que el de los Estatutos valenciano y

\footnotetext{
35 Tienen previsiones similares los Estatutos de Andalucía (13), Aragón (art. 6.3), Baleares (art. 13.3) o Castilla y León (art. 8.3).

${ }^{36}$ STC 247/2007, FJ.22.

37 M. A. APARICIO PÉREZ y M. BARCELÓ I SERRAMELERA, "Los derechos públicos..., op cit, p. 24.

38 Este sería el caso de Extremadura que dedica los artículos 6 y 7 a regular, respectivamente, los derechos y principios rectores de los extremeños, y respecto a los derechos en esencia hace una referencia a los derechos protegidos en la Constitución, por lo que a efectos prácticos se trata de un Estatuto que en este aspecto apenas aporta nada respecto a la regulación anterior a las reformas. En esta línea también puede incluirse la Ley Orgánica de reintegración y amejoramiento del Régimen Foral de Navarra cuya regulación aún es más escueta que la del Estatuto extremeño limitándose a un solo artículo en el que se remite a la Constitución en todo lo relativo a «derechos, libertades y deberes fundamentales».
} 
balear $^{39}$. Estos últimos agrupan, en un único título, algunos derechos y principios, sin sistematización alguna, y sin hacer una distinción básica como sería agrupar derechos y principios en capítulos diferenciados. En un punto medio entre los tres primeros y estos dos últimos se encontraría el Estatuto de autonomía de Aragón que, si bien distingue entre principios y derechos, no prevé un sistema de garantías, como sí lo hacen los inicialmente mencionados.

La presencia de un sistema de garantías es quizá una de las notas más destacadas de las nuevas declaraciones de derechos. Aunque los derechos contemplados en las demás declaraciones no pierden su sustantividad solo por la ausencia de un sistema de garantías propio. Ahora bien, no puede obviarse que contar con un sistema de protección articulado en el propio Estatuto dota de mayor fortaleza a los bienes jurídicos por él amparados, y contribuye notablemente a reforzar su naturaleza de derechos.

Resumiendo, tenemos estatutos que hacen una distinción que, a la postre, puede resultar crucial a la hora de establecer la efectividad que las declaraciones derechos pueden tener. Dicha distinción resultará de gran utilidad a la hora de determinar la exigibilidad de los preceptos que van a configurar cada una de las declaraciones de derechos. La relevancia de esta distinción radica en las consecuencias derivadas de gozar de una u otra consideración, de ahí que convenga, aunque sea someramente, comenzar analizando las implicaciones derivadas de ostentar la condición de derecho o de principio rector.

Para ser precisos, debe tomarse en cuenta que, en nuestro ordenamiento, bajo el nomen iuris de derechos se configuran auténticos derechos subjetivos, pero también derechos que, manteniendo su naturaleza como tales, vienen a requerir de un desarrollo legislativo para su plena eficacia ${ }^{40}$. Ahora bien, esto último no debe llevarnos a negar su condición de derechos subjetivos sin perjuicio de que, como ha reconocido el Tribunal Constitucional, «cuando se opera con esa reserva de configuración legal el mandato constitucional puede no tener, hasta que la regulación se produzca, más que un mínimo contenido» ${ }^{41}$. Siendo esto cierto, queda patente que la diferencia esencial radica en la distinción entre derechos subjetivos y principios rectores, porque si bien entre los derechos se pueden hacer clasificaciones en función de su grado de exigibilidad, no es menos cierto que en todos late un mínimo común de garantías.

\footnotetext{
39 Tanto el Estatuto valenciano como el balear hacen una remisión a una futura Carta de derechos para la concreción y desarrollo de los derechos y principios que informarán la actuación de sus Administraciones ante los ciudadanos. Además, debemos referir que en el caso del Estatuto valenciano no se configuran principios, si nos atenemos a la denominación que el texto autonómico da a los contenidos regulados en su Título II, más allá de que, por su estructura y contenidos, estamos ante principios orientadores para la actuación de los poderes públicos valencianos.

${ }^{40}$ Sirvan como ejemplo el derecho a la objeción de conciencia del artículo 30.2 CE o el derecho de fundación para fines generales del 34.1 CE.

${ }^{41}$ SSTC 15/1982, de 23 de abril, FJ. 8; reiterado por la 254/1993, de 20 de julio, FJ. 6 y 31/1994, de 31 de enero, FJ. 7.
} 
Sin embargo, como más adelante incidiremos, esa distinción entre derechos plenos y aquellos que hacen un llamado al legislador sí será relevante a la hora de determinar su naturaleza en el caso de las declaraciones de derechos estatutarias debido a la interpretación de las mismas que ha hecho el TC.

Esa es la razón por la que, antes de entrar a analizar la naturaleza jurídica de los preceptos estatutarios, conviene delimitar qué se entiende tanto por derecho subjetivo como por principio rector en aras de contar con unas categorías generales a partir de las cuales tratar de clarificar la naturaleza de los "derechos" estatutarios. Debo advertir que no se busca el hacer un trabajo acerca de estos conceptos, cuyo sentido, alcance y naturaleza han sido objeto de una prolífica discusión tanto por la doctrina jurídica como por la filosófica ${ }^{42}$. El objetivo aquí perseguido es mucho más humilde, proporcionar una definición que sirva como punto de referencia para orientar al lector acerca de cuáles son las características principales en las que nos basaremos para calificar la naturaleza de los preceptos estatutarios. Por ese motivo, a la hora de decantarnos por una definición u otra de estos conceptos, se ha tomado como referencia el que contemple las consecuencias jurídicas de ambas categorías.

Las premisas anteriores llevan a que, en el caso de los principios rectores, se vaya a partir de lo dispuesto en la Constitución para definir sus características. Sin embargo, en el caso de los derechos subjetivos considero que por su claridad resulta de mayor utilidad una definición como la enunciada por ROBLES MORCHÓN, el cuál define a los derechos subjetivos como el «poder concreto organizado externamente e internamente por el ordenamiento jurídico, que comprende un conjunto de posibilidades de acción y de omisión, cuyo ejercicio se deja a la libre disposición del titular, y entre cuyas facultades se encuentra la posibilidad de acudir a los jueces en busca de protección [mediante una acción procesal] $\gg^{43}$.

De la definición se derivan una serie de características que nos permitirán identificar si nos encontramos ante un derecho subjetivo. La primera es que ha de estar positivado, y ha de estarlo de modo tal que su tenor nos permita determinar cuáles son los poderes y facultades que en él se amparan, por lo que deben estar identificados tanto los sujetos activos como pasivos así como la conducta objeto de protección. Asimismo, y ésta será la característica que más nos interesará, estaremos ante un derecho subjetivo cuando entre las facultades que su configuración ofrece se encuentre la posibilidad de acudir en defensa del mismo ante la jurisdicción ordinaria. Es decir, ha de poder ejercitarse dicha defensa judicial fundamentándola en el contenido del precepto que regula el derecho subjetivo que, en este sentido, goza de autonomía plena

\footnotetext{
42 Qué se ha de entender por derecho subjetivo es una pregunta a la que han tratado de responder, entre otros: Jhering, Kelsen, Windscheild o Ulrich K. Preuss.

43 G. ROBLES MORCHÓN, Teoría del derecho: fundamentos de teoría comunicacional del derecho, Civitas, Madrid, 2010, p. 707.
} 
pues no requiere de un desarrollo posterior para su defensa. Por lo tanto, no sería necesaria una interpositio legis/atoris que desarrollara el derecho en cuestión, sin perjuicio de que tal desarrollo pudiera ser conveniente o permitiera un mayor grado de concreción en el ejercicio de dicha facultad.

La definición de derecho subjetivo proporciona ciertas características de los mismos que, por exclusión, nos ayudarán a comprender y delimitar las características de los principios rectores. Esta afirmación cobra pleno sentido si pensamos en la facultad de plantear una acción procesal. Dicha cualidad de los derechos subjetivos es, además de una condición sine qua non de los mismos, un indicio para identificar a los principios rectores. $Y$ ello debido a que su ausencia nos permitirá descartar que nos encontremos ante un derecho subjetivo y servirá como criterio para calificar la naturaleza de lo que el estatuyente ha denominado como derecho.

Teniendo esto en cuenta, conviene proceder a dar una noción, lo más ajustada posible, de lo que en el ordenamiento jurídico español se entiende por principios rectores. Debe tenerse en cuenta que con el nombre de principios rectores se identifican una serie de preceptos que en la Constitución española se corresponden con el capítulo III del Título I de la Constitución. Bajo tal denominación se agrupan preceptos de diversa índole, abarca desde los llamados derechos sociales (v. gr. El derecho a la protección de la salud o a un medioambiente adecuado) hasta mandatos y orientaciones para el legislador así como la protección de determinados fines considerados valiosos para el interés general (sirvan como ejemplo la promoción de la participación de la juventud en el desarrollo político, social, económico y cultural o la distribución equitativa de las rentas, tanto las personales como las regionales).

Llegados a este punto ha de advertirse que si se toma como referencia lo que dispone la Constitución respecto a los principios rectores para hablar de los principios estatutarios es porque considero que la doctrina aplicable a estos es la misma que se aplica para los constitucionalmente definidos ${ }^{44}$.

Como acabamos de señalar, bajo la rúbrica de principios rectores se agrupan preceptos de variada condición, pero todos ellos comparten una serie de rasgos comunes que ayudan a definirlos e identificarlos. Para bosquejar la fisionomía que caracteriza a los principios rectores tomaremos como referencia la propia Constitución. La Norma Fundamental de nuestro ordenamiento señala, en su artículo 53, concretamente en su apartado 3, que los principios rectores: «informarán la legislación positiva, la práctica judicial y la actuación de los poderes públicos. Sólo podrán ser alegados ante la Jurisdicción ordinaria de acuerdo con lo que dispongan las leyes que los desarrollen».

El contenido de este precepto refleja las características que identifican a los principios rectores y sirve como guía para determinar cuándo nos encontramos ante un principio en el caso de las declaraciones de derechos

\footnotetext{
${ }^{44}$ En ese sentido, C. ROSADO VILLAVERDE, La regulación estatutaria de los derechos y libertades, Dykinson, Madrid, 2012, p. 84.
} 
estatutarias. Esos rasgos definitorios serían: en primer lugar que los principios requieren de un desarrollo legislativo posterior para que su contenido goce de protección jurisdiccional, es decir, no tienen autonomía plena. Esta es quizá la característica que, de un modo más claro, traza la diferencia entre los derechos subjetivos y principios.

Otra de las características es que los principios tienen como finalidad no tanto la configuración de un poder concreto con unas características determinadas, sino servir como orientación y límite al legislador, quien ha de tomarlos como referencia en la medida en que informan de cuáles son los fines que ha de perseguir en su actuación y los mínimos que ha de respetar; si bien es cierto que le conceden un amplio margen de actuación. Debe señalarse que, aunque en los derechos subjetivos también subyace esta función de orientación, el grado de libertad que proporcionan al legislador es mucho menor que el de los principios.

El Tribunal Constitucional ha afirmado la necesidad de modulación de los artículos 39 a 52 de la Constitución en los términos del artículo 53.3 de la Constitución ${ }^{45}$, precepto que «impide considerarlos normas sin contenido, obligando a los poderes públicos a tenerlos presentes en la interpretación tanto de las restantes normas constitucionales como de las leyes» ${ }^{46}$.

Como se acaba de demostrar, las consecuencias de otorgar una consideración u otra a un determinado bien jurídico son ciertamente relevantes. Sin embargo, no basta con darles una denominación u otra para determinar su naturaleza, sino que, como se ha insinuado más arriba al mencionar la existencia de un mínimo exigible, la estructura y grado de concreción en su formulación resultarán fundamentales a la hora de determinar su naturaleza, porque podemos encontrarnos con preceptos que configuren como derechos lo que en la realidad es un principio rector. Del mismo modo que, dentro del ámbito de los derechos, no será lo mismo, como veremos a la hora de enfrentarnos a su exigibilidad, aquellos derechos que requieran de un desarrollo posterior por el legislador (en los que solo existiría un mínimo alegable ante los tribunales) que los derechos que, por cómo han sido configurados por el estatuyente, cuenten con una estructura que los haga exigibles en toda su extensión sin necesidad de extraer de su ordenación mínimo alguno.

Sin embargo, siendo relevante las distinciones en torno al grado de concreción de los que consideremos derechos a la hora de tratar la exigibilidad de los derechos estatutarios, será la distinción entre derechos subjetivos y los principios la que marque las grandes diferencias. Esa es la razón por la que se ha comenzado este epígrafe haciendo una referencia a cómo los distintos estatuyentes habían afrontado la regulación de las cartas de derechos y si habían distinguido, o no, entre derechos y principios rectores. Ahora bien, aun siendo la configuración realizada por el estatuyente una referencia importante a la hora de determinar la naturaleza de los preceptos en juego, no lo es menos su estructura, nivel

${ }^{45}$ Cfr. STC 80/1982, de 20 de diciembre, FJ. 1.

${ }^{46}$ SSTC 19/1982, de 5 de mayo y 14/1992, de 10 de febrero. 
de certeza y exigibilidad. Por ello se procederá a realizar un análisis más detallado de las declaraciones de derechos centrándonos en su contenido y tratando de evitar que el nomen iuris pueda llegar a condicionarnos, aunque será, como no puede ser de otro modo, una referencia importante; quizá, incluso, un punto de partida que podrá confirmarse o desmentirse en función de si en el precepto concreto concurren, o no, las condiciones que lo acrediten como tal.

\subsection{Una amplia gama de principios rectores}

Como se ha indicado, algunas de las declaraciones de derechos estatutarias hacen una distinción clara entre los preceptos que configuran como derecho y los que son principios. Otros Estatutos, por el contrario, no han llevado a cabo una sistematización tan clara pero, más allá de la sistemática por la que el estatuyente haya optado, lo relevante será determinar la naturaleza del contenido estatutario objeto de análisis. Esto conlleva la necesidad atender a la sustantividad de cada precepto.

Siendo esta la situación de partida, a la hora de analizar la naturaleza de las declaraciones de derechos contenidas en los Estatutos de Autonomía conviene hacer una clasificación de los mismos ${ }^{47}$. En dicha tarea se tomará en consideración cómo han sido denominados por el estatuyente, su origen y la configuración de los preceptos para poder identificar aquellos que, siendo considerados como derechos, su naturaleza revele que se trata de principios.

Tomando esas variables en consideración, pueden agruparse los principios en dos categorías: la primera estaría conformada por aquellos principios denominados como tales y considerados así por el propio estatuyente. Se trataría de preceptos cuya naturaleza no es discutida y las consecuencias que de ellos derivan coinciden con la categoría general de los principios que hemos definido. La segunda de las categorías sería la integrada por aquellos preceptos a los que el estatuyente ha dado veste de derechos pero que en realidad no son derechos subjetivos sino que, su naturaleza y las consecuencias jurídicas que conllevan, encajan con la de los principios. A este segundo grupo será al que prestemos una mayor atención. Pero antes de centrarnos en su estudio conviene realizar algunas precisiones sobre la primera de las categorías aquí referidas.

Como se ha indicado, ese primer grupo estaría compuesto por aquellos principios cuya naturaleza como tales no resulta controvertida. Sin embargo, esa categoría contiene principios de orígenes diferentes lo que

\footnotetext{
47 En este sentido, EXPÓSITO GÓMEZ realiza una interesante clasificación, en la que toma en consideración el contenido de los derechos estatutarios, identificándolos como «derechos en blanco» y «derechos de configuración legal». Los primeros representarían aquellos preceptos que pese a su denominación como derechos no hay nada en ellos que les haga merecedores de tal condición. Respecto a los derechos de configuración legal, éstos se caracterizarán porque, pese a la necesidad de un desarrollo por parte del legislador, hay en ellos un contenido mínimo, lo que les aproxima más a la condición de derechos. Cfr. E. Expósito Gómez, "Declaraciones estatutarias ¿de derechos? Un análisis a la luz de las SSTC 247/2007 y 31/2010", Teoría y Realidad Constitucional, No 27, 2011, pp. 495-496.
} 
conlleva consecuencias notables. $Y$ es que, junto a los principios estatutarios que vienen a recoger, con reproducciones más o menos exactas, los principios rectores del Capítulo III del Título primero de la $\mathrm{CE}^{48}$, nos encontramos que los Estatutos de la primera década del dos mil han incorporado algunos principios nuevos que no encuentran su correlativo en los principios rectores constitucionales.

En ese sentido debemos apuntar que los Estatutos han profundizado y ampliado significativamente el catálogo de principios, incorporando algunos nuevos como la lucha contra el sexismo, la xenofobia, la homofobia y el belicismo. A la vez han desarrollado otros que abarcan de manera específica a distintos colectivos de la sociedad como pueden ser las personas mayores o los inmigrantes. Sirvan como ejemplo de lo anterior los artículos: $37.1 .1^{\circ}, 40,90$ y $24^{\circ}$ del Estatuto de Autonomía de Andalucía. El 41 del Estatuto de Autonomía de Cataluña a su vez promueve una perspectiva de género en la actuación de los poderes públicos. Y el 16.10 del Estatuto de Castilla y León resulta interesante debido a que formula un principio destinado a combatir un problema específico de su Comunidad como es la despoblación. En nuestra opinión, la ampliación del catálogo de principios resulta positiva porque permite adaptar los principios a las situaciones particulares a que pueda enfrentarse el legislador autonómico en sus respectivas Comunidades.

Debe incidirse que esta distinción en cuanto al origen de los principios tiene cierta relevancia. En tanto que, aquellos principios que cuentan con un análogo en la Norma Suprema de nuestro ordenamiento tienen como fundamento de su carácter vinculante la propia Constitución y no el Estatuto que los recoge. Aunque no es menos cierto que el estar recogidos en la norma institucional básica de las CCAA les dota de un posición jurídica reforzada dentro del ordenamiento autonómico. Refuerzo que se fundamenta en dos aspectos a tomar en consideración: su mayor rigidez y su fuerza vinculante.

Por lo que respecta a la rigidez: los principios que tienen su origen en la Constitución se ven reforzados al ser recogidos en el Estatuto de Autonomía en lugar de en cualquier otra ley. Esto se debe a la posición de los Estatutos en el ordenamiento jurídico ${ }^{49}$ y al procedimiento para la reforma de los mismos, mucho más agravado ${ }^{50}$. Todas esas características dotan a la posición de los principios estatutarios de un mayor blindaje

\footnotetext{
${ }^{48}$ Como puede ser la promoción de la participación en la vida social y política o el libre acceso a la cultura o la vivienda.

${ }_{49}$ Como ya tempranamente señaló el TC con la STC 76/1983, de 5 de agosto, de la LOAPA. Sobre la función constitucional de los Estatutos de Autonomía, vid. J. L. CASCAJO CASTRO, "Observaciones sobre la denominada función constitucional de los Estatutos de Autonomía", Teoría y Realidad Constitucional, núm. 23, 2009, pp. 133-177.

50 La reforma estatutaria, en concordancia con la naturaleza bifronte del Estatuto conlleva que además de la voluntad del Parlamento autonómico deba concurrir la del Parlamento estatal, a lo anterior se añade, en el caso de algunas CCAA (como fue el caso de Cataluña) la necesidad de someter el Estatuto a un referéndum de aprobación.
} 
frente a actuaciones legislativas que pudieran mermar la protección de que tales principios aseguran, por mínima que esta sea ${ }^{51}$.

El segundo aspecto que se fortalece al recoger los Estatutos estos principios constitucionales se concreta en una mayor vinculación del legislador autonómico a los mismos ${ }^{52}$. El fundamento de esta afirmación radica en que el legislador autonómico se verá conminado a tomarlos en consideración a la hora de desarrollar su política legislativa no solo porque la Constitución así lo preceptúe (lo que ya es importante), sino porque su Estatuto así se lo pide. Aunque pueda parecer una cuestión menor, en tanto que podría argumentarse (no sin razón) que al estar en la Constitución su función ya está garantizada (y lo está); es lo cierto que, tomando en consideración la naturaleza de los principios cuya fuerza radica, sobre todo, en ser orientación de la labor del legislador, el hecho de que el estatuyente autonómico haya apreciado que tal principio merece ser recogido en la norma de cabecera de la CA tiene consecuencias. Tiene consecuencias puesto que supone decirle al legislador autonómico que los bienes jurídicos que con ese principio se intentan proteger son valiosos para los ciudadanos de la CA. Esto supondrá que se verá doblemente conminado a desarrollarlos, en la medida en que los partidos de la oposición, las instituciones de protección de los derechos e incluso la opinión pública contarán con más elementos de presión frente al legislador, lo que les dota de una mejor posición para que se puedan desarrollar ${ }^{53}$.

Por lo que respecta los principios de nuevo cuño, el hecho de no encontrar su correlativo en la Constitución supone que su fuerza, a diferencia de los anteriores, no emanará de ésta sino de los Estatutos de Autonomía que los reconocen. La inclusión de nuevos principios, aunque en menor grado que si fueran derechos, tiene una consecuencia importante: condiciona las opciones del legislador autonómico cuyas posibilidades de actuación se ven, aunque sea en un grado mínimo, reducidas por la inclusión de nuevos principios que no puede contravenir con su actuación.

Sin embargo, y dejando a salvo los matices apuntados, en lo tocante a su naturaleza jurídica no hay diferencia entre los nuevos principios estatutarios y aquellos que tienen su análogo en la Constitución. Ambos cumplen la misma función y tienen las características que conforman a todos los principios, y que se corresponden con las que hemos referido al definir los principios rectores.

Pero, como se ha advertido, no son los principios que como tal reconocen los estatutos los que suscitan controversia. El auténtico conflicto radica en las declaraciones de derechos de los nuevos estatutos,

51 F. LÓPEZ MENUDO, "Los derechos sociales en los Estatutos de Autonomía", Administración de Andalucía. Revista andaluza de Administración Pública, No 73, 2009, pp. 164 y 165.

${ }^{52}$ C. ROSADO VILLAVERDE, La regulación estatutaria..., op. cit., p. 88.

53 T. QUADRA-SALCEDO JANINI, "EI régimen jurídico de los derechos sociales estatutarios. Reflexiones tras la STC 247/2007, de 12 de diciembre", Revista General de Derecho Constitucional, No 5, 2008, p. 18. 
concretamente en aquellos preceptos que catalogan como derechos lo que, en la práctica, son principios. En estos centraremos nuestra atención, pues no se trata de un simple problema de denominación sino de las consecuencias jurídicas que derivan para los ciudadanos el que tengan una u otra naturaleza. El hecho de que se haya denominado como derecho algo que es un principio, tendría el mismo inconveniente que puede predicarse de los principios rectores constitucionales ${ }^{54}$. Debe recordarse que en el Capítulo III se enuncian con el nombre de derechos ${ }^{55}$ lo que en realidad son principios, tal y como su naturaleza viene a acreditar, y no solo por estar bajo la rúbrica de los principios rectores, sino por su configuración y por lo dispuesto en el artículo $53.3 \mathrm{CE}$.

Por lo tanto, sí es un problema el que a un principio se le atribuyan unas consecuencias jurídicas que, por su propia naturaleza, no resultan realizables, generando lo que BIGLINO denominó «los espejismos de la tabla de derechos ${ }^{56}$. En la misma línea se posiciona FERRERES COMELLA quién critica las reformas estatutarias poniendo el acento, precisamente, en la decepción que pueden generar en la ciudadanía ${ }^{57}$. Esta es la razón por la que resulta crucial identificar a aquellos que no son derechos subjetivos sino principios, al menos en lo que a efectos jurídicos se refiere.

Esta labor cobra un mayor valor si cabe en los supuestos en que las normas autonómicas han llevado a cabo una sistematización en la que se distingue entre derechos y principios rectores. En estos casos los problemas se multiplican pues el estatuyente ha querido que no se consideren principios sino derechos. Hacer tal distinción e incluirlos en la categoría de derechos es un indicio claro de que lo que se pretendía era reconocer auténticos derechos subjetivos y no principios. Sin embargo, en muchos casos, a esa intención no la ha acompañado una configuración adecuada para poder atribuirles las consecuencias jurídicas que derivarían de un derecho subjetivo. Es en este tipo de preceptos en los que, de un modo general, centraremos nuestro análisis.

A la hora de analizar estos, llamémosles de entrada derechos, se ha de tomar en cuenta que, como con acierto señala el TC, «bajo el término «derecho» se comprenden tanto verdaderos derechos subjetivos como cláusulas de legitimación para el desarrollo de determinadas opciones legislativas» ${ }^{58}$. Por esta razón resulta crucial establecer la naturaleza de las disposiciones estatutarias en aras de determinar, en epígrafes

\footnotetext{
${ }^{54}$ Es decir, su carácter promisorio y sobre todo el riesgo de crear falsas expectativas en la población, siendo el mayor reflejo de esta problemática el artículo 47 de la CE como recuerda BIGLINO CAMPOS en, P. BIGLINO CAMPOS, "La reforma de los Estatutos de Autonomía: un problema que se desplaza, otro que se agudiza y otros por resolver", Corts: Anuario de derecho parlamentario, No 25, 2011, p. 26.

${ }^{55}$ Además del derecho a una vivienda digna del artículo 47, tenemos, entre otros: el derecho a la salud o a un medio ambiente adecuado.

${ }^{56}$ P. BIGLINO CAMPOS, "Los espejismos de la tabla de derechos" en Derechos, deberes y principios en el nuevo Estatuto de Autonomía de Cataluña, Centro de Estudios Políticos y Constitucionales, Madrid, 2006, p. 53 y ss.

${ }^{57}$ V. FERRERES COMELLA, "Derechos, deberes y..., op. cit., pp. 33 - 34.

${ }^{58}$ STC 31/2010, FJ. 16.
} 
venideros, su exigibilidad. Para llevar a cabo dicha tarea se tomará en cuenta su formulación para así comprobar si el contenido de los preceptos que los desarrollan es compatible con el que sería propio de un derecho subjetivo o, por el contrario, se trata de principios.

En ese sentido, lo primero que debe señalarse es que, con carácter general, la mayoría de los preceptos denominados como derechos contienen derechos sociales, es decir, derechos de tipo prestacional. La mayoría de ellos formulados de modo tal que otorgan un amplio margen de actuación al legislador al que, en muchos de los casos, hacen llamados para que lleve a cabo su desarrollo normativo. Estas son características que, de entrada, resultarían más acordes a lo que hemos definido como principios. Sin embargo, la razón principal para inclinar la balanza hacia la consideración de muchos de los preceptos estatutarios como principios es el alto grado de indeterminación de los mismos. Los otros dos argumentos (el carácter prestacional y la necesidad de un desarrollo legislativo posterior) se pueden considerar indicios que refuerzan la idea, pero nunca razón suficiente para negarles la naturaleza de derechos subjetivos.

Porque, siendo cierto que los derechos de carácter prestacional suelen estar reconocidos como principios en los textos constitucionales ${ }^{59}$, precisamente por implicar la necesidad de acción por parte de las Administraciones y por requerir de una considerable cantidad de recursos financieros de la que no siempre es posible disponer ${ }^{60}$. Por otra parte, no es menos cierto que también se reconocen como derechos subjetivos genuinos derechos sociales de carácter prestacional, siendo quizá el ejemplo más paradigmático el derecho a la educación ${ }^{61}$.

En lo referente a la necesidad de desarrollo legislativo posterior, aun siendo este un indicio más fuerte que el carácter social de los derechos, tampoco debería ser una razón suficiente para negar la condición de derecho subjetivo a un determinado precepto ${ }^{62}$. En este caso enfatizo que no debería porque es lo cierto que, el TC, tanto en su sentencia 247/2007 como en la $31 / 2010$, sí parece considerarlo razón suficiente ${ }^{63}$. Sin embargo, esto supone aplicarles a los derechos estatutarios una doctrina diferente de la que se aplica a los derechos constitucionales. Entre estos últimos, tal como se ha referido, hay derechos que, haciendo un llamamiento al legislador para su desarrollo, no por ello se les niega su naturaleza de derecho subjetivo, aunque sea solo con un alcance mínimo para proteger su núcleo esencial. Esta debería haber sido la línea seguida

\footnotetext{
${ }^{59}$ Sirva como ejemplo nuestra propia CE que reconoce como principios derechos sociales de gran relevancia como el de la salud o la seguridad social.

60 P. BIGLINO CAMPOS, "La reforma de los Estatutos..., pp. 23 - 27. En las que pone de manifiesto los problemas que va a generar la imposibilidad de satisfacer los derechos consagrados en los nuevos Estatutos.

${ }^{61}$ Artículo $27 \mathrm{CE}$.

62 En esa línea se pronuncian APARICIO y BARCELÓ consideran que «una remisión al posterior desarrollo legislativo autonómico del derecho en cuestión (...) no equivale (...) a su vaciamiento». En M. A. APARICIO PÉREZ y M. BARCELÓ I SERRAMELERA, "Los derechos públicos..., op. cit., p. 30.

${ }^{63}$ Vid. SSTC 247/2007, FJ. 13 - 15 y STC 31/2010, FJ. 16 - 19, especialmente el 16.
} 
en el caso de los derechos estatutarios, porque «allí donde se produce una remisión al posterior desarrollo legislativo autonómico del derecho en cuestión en la mayoría de los casos no se genera un aplazamiento de vigencia sino un aplazamiento de especificación de contenido; lo que no equivale, desde luego, a su vaciamiento» ${ }^{64}$.

Pero la verdad es que, como se ha insinuado en el párrafo anterior, el TC no ha procedido a hacer una interpretación en este sentido para los derechos estatutarios, como pusiera de manifiesto LÓPEZ MENUDO al señalar que la STC 247/2007 «viene a elevar a dogma la afirmación de que es imprescindible la interpositio legislatoris para la creación de un derecho ${ }^{65}$. De hecho, si nos atuviéramos a la doctrina que el TC formuló con ocasión de la sentencia del Estatuto de la Comunidad Valenciana, nos encontraríamos en la tesitura de que todos los derechos reconocidos por los Estatutos de Autonomía eran en realidad «mandatos, orientaciones u objetivos, dirigidos a los poderes públicos autonómicos» ${ }^{66}$. Quedando a salvo de esta degradación a principios solo los derechos subjetivos derivados de previsiones constitucionales, es decir, se reduciría a los derechos referentes a la organización de las instituciones de la $\mathrm{CA}^{67}$.

Sin embargo, esta doctrina pareció flexibilizarse un poco con la sentencia relativa al Estatuto de Cataluña, que mantiene la línea general ${ }^{68}$ enunciada con la sentencia de 2007 , pero elimina la referencia a que solo los derechos institucionales pueden ser derechos subjetivos. Aunque debe reconocerse que si bien «el Tribunal no niega su existencia, [...] tampoco los identifica ni los califica» ${ }^{69}$. Lo que hace en la sentencia $31 / 2010$ es confirmar que «en el nuevo Estatuto catalán se prodiga sobre todo, según veremos, sin que falten proclamaciones de derechos subjetivos stricto sensu, el segundo tipo de derechos, es decir, mandatos de actuación a los poderes públicos, ya estén expresamente denominados como «principios rectores», ya estén enunciados literalmente como derechos» ${ }^{70}$.

La posición adoptada por el Alto Tribunal parece más cercana a la realidad jurídica que los Estatutos vienen a reconocer ${ }^{71}$. Parecía excesivo reducir los derechos subjetivos que los Estatutos pueden reconocer a aquellos ligados a la configuración de las instituciones. Sin embargo, a efectos prácticos, lo que este pronunciamiento supone es que, a la hora

\footnotetext{
${ }^{64}$ T. QUADRA-SALCEDO JANINI, "El régimen jurídico..., op. cit., p. 23.

${ }^{65}$ F. LÓPEZ MENUDO, "Los derechos sociales..., op. cit., p. 156. En la misma línea $T$. QUADRA-SALCEDO JANINI, "El régimen jurídico..., op. cit., p. 30 y ss., este último señala que la STC 247/2007 «niega la condición de derechos a los derechos estatutarios».

${ }^{66}$ STC 247/2007, FJ. 15.

67 Ibídem.

${ }^{68}$ Cfr. E. EXPÓSITO GÓMEZ, "Derecho y garantías", Revista Catalana de Dret Públic, Especial Sentencia sobre el Estatuto, No Extra 1, 2010, p. 168.

69 Ibídem, p. 170.

${ }^{70}$ STC 31/2010, FJ. 16.

${ }^{71}$ Así lo pone de manifiesto AGUDO ZAMORA al incluir entre las aportaciones de la STC $31 / 2010$ «la «validación» constitucional de la inclusión de un catálogo de derechos en los Estatutos de Autonomía». En M. A. AGUDO ZAMORA, "La efectiva constitucionalidad de la regulación de derechos estatutarios en la STC 31/2010", Teoría y Realidad Constitucional, No 27, 2011, p. 480.
} 
de determinar la naturaleza de las declaraciones de derechos estatutarias, no podemos hacer tabla rasa y decir que todos son mandatos y orientaciones al legislador autonómico. En ese sentido resulta acertada la descripción que de los derechos reconocidos en los nuevos Estatutos ofrecen APARICIO y BARCELÓ: «en general [sin excluir tal posibilidad] no son derechos de exigibilidad directa [...] pero tampoco propiamente, al menos en su totalidad, son derechos de configuración legal» ${ }^{72}$. Por consiguiente, antes de calificar la naturaleza jurídica de un determinado precepto, debemos analizarlo sin apriorismos y prestando atención a cómo está formulado, a las garantías que lo amparan y a las facultades que otorga a su titular.

La toma en consideración de esos aspectos nos permitirá identificar aquellos preceptos que tengan naturaleza de principios aunque estén revestidos como derechos. Y ello resulta crucial porque en la práctica no conllevan para sus titulares las facultades que de un derecho subjetivo dimanan y, por lo tanto, no pueden considerarse como tales. Y de hecho, la previsión realizada por el Estatuto catalán de aprobar por Ley una Carta de Derechos ${ }^{73}$ como medio de garantía para los derechos estatutarios viene a confirmar que el propio estatuyente era consciente de la indeterminación que caracterizaba a algunos de los preceptos del Estatuto.

Lo hasta ahora señalado se entiende mejor si lo ilustramos con algunos ejemplos. En ese sentido, el caso del derecho a la vivienda, que el Estatutos catalán (art. 26) ${ }^{74}$ configura adolece de una falta de concreción tal que no podemos considerarlo como derecho; pues ni se define su objeto con un grado de precisión aceptable, ni las condiciones que han de identificar a los potenciales titulares de ese derecho están claras ${ }^{75}$.

Otro ejemplo, no menos claro que el anterior, sería el del derecho a acceder a una renta garantizada a personas o familias en situación de pobreza regulado en el artículo 24.3 del Estatuto de Cataluña. En términos similares, pero destinando esa renta a los ciudadanos en riesgo de

72 M. A. APARICIO PÉREZ y M. BARCELÓ I SERRAMELERA, "Los derechos públicos..., op cit, p. 24.

73 Vid. Artículo 37 Estatuto Autonomía de Cataluña.

${ }^{74}$ Artículo 26: «Las personas que no disponen de los recursos suficientes tienen derecho a acceder a una vivienda digna, para lo cual los poderes públicos deben establecer por ley un sistema de medidas que garantice este derecho, con las condiciones que la ley determine».

${ }^{75}$ Un poco más preciso es el andaluz, quien en el artículo 25 articula una propuesta de la que sí podrían derivarse obligaciones específicas para los poderes públicos andaluces en el ámbito de la promoción de vivienda, si bien, carece de cierta concreción en cuanto a la regularidad y condiciones que deben caracterizar a esa promoción, como puede comprobarse de la lectura del artículo, que a continuación se transcribe: «Para favorecer el ejercicio del derecho constitucional a una vivienda digna y adecuada, los poderes públicos están obligados a la promoción pública de la vivienda. La ley regulará el acceso a la misma en condiciones de igualdad, así como las ayudas que lo faciliten».

Sobre el derecho a la vivienda en los Estatutos de Autonomía vid. M. J. Agudo-Zamora, "Derecho a la vivienda y reformas estatutarias", Anuario da Facultade de Dereito da Universidade da Coruña, núm. 14, 2010, pp. 163-184. 
exclusión social, se pronuncia el artículo 13.9 del Estatuto de Castilla y León. En uno y otro caso, pese a que podría pensarse que al menos se identifica a los titulares de ese derecho, lo cierto es que no lo hacen, pues no se estipulan unas condiciones mínimas que permitan individualizarlos. Supuestos de este tipo son en los que las palabras de FERRERES COMELLA tienen mayor vigencia pues, en efecto, «aparecen nominalmente como derechos, pero se garantizan bajo unas condiciones que los convierten, en realidad, en meros principios rectores ${ }^{76}$.

\subsection{No todos son principios, hay auténticos derechos subjetivos}

En materia de derechos subjetivos resulta necesario hacer una consideración previa relativa al carácter de los preceptos estatutarios. Se trata de preceptos que, en su mayoría, regulan derechos de carácter prestacional, tal como se ha señalado al tratar los principios estatutarios. De hecho, tal y como ha apuntado la mayor parte de la doctrina, las reformas estatutarias tenían como uno de sus principales objetivos elevar a la categoría de derechos los principios rectores constitucionales ${ }^{77}$.

Aunque si de desarrollo de preceptos constitucionales se trata, no podemos dejar de mencionar otra de las actuaciones llevadas por el estatuyente en materia de derechos, y es que no puede obviarse que los Estatutos reformados también han incorporado en sus declaraciones de derechos cuestiones relativas a derechos fundamentales de la Constitución ${ }^{78}$. Lo que buscaban era, específicamente, concretar aspectos secundarios de los derechos fundamentales que caían dentro del marco competencial autonómico. Por supuesto, con esto no estoy diciendo que los estatutos estén regulando derechos fundamentales ${ }^{79}$, algo que les resulta de todo modo imposible, pues solo la Constitución puede reconocerlos y solo el legislador estatal por medio de Ley Orgánica (artículo $81.1 \mathrm{CE}$ ) puede desarrollarlos en sus aspectos esenciales ${ }^{80}$. Sin embargo, si se respeta esa reserva de Ley Orgánica, sí queda un espacio en el que el legislador ordinario puede actuar. Esta es la razón por la que

\footnotetext{
${ }^{76}$ V. FERRERES COMELLA, "Derechos, deberes y..., op. cit., p. 33.

77 Con las siguientes palabras definía QUADRA-SALCEDO el objetivo de la reforma estatutaria en este punto: "intento de transformación de algunos principios rectores de la política social y económica en derechos subjetivos mediante su inclusión en el estatuto de autonomía con la categoría de derechos". En T. QUADRA-SALCEDO JANINI, "EI régimen jurídico..., op. cit., p. 14.

78 Destacan en este ámbito los de carácter educativo.

79 Aunque en este sentido el apunte que realiza CANOSA USERA acerca de la aspiración de los derechos estatutarios a ser considerados fundamentales no debe caer en saco roto, debe servir para estar atentos a desarrollos futuros, pero en las declaraciones actuales no están en condiciones de satisfacer tales aspiraciones. R. CANOSA USERA, "La declaración de derechos..., op. cit., p. 89.

${ }^{80}$ Así lo ha confirmado el TC, con mucha anterioridad a las reformas estatutarias de la primera década del 2000. SSTC: 101/1991, de 13 de mayo; 292/2000, de 30 de noviembre y 53/2002, de 27 de febrero. En ellas se delimita qué se entiende por contenido esencial, pero también se señala el campo de actuación del legislador ordinario en la medida en que se define el alcance de la reserva de Ley Orgánica. Entendiéndose que aquello que quede fuere de dicha reserva de Ley Orgánica es disponible tanto por el legislador autonómico como por el estatuyente.
} 
ROSADO VILLAVERDE considera que la concreción por el Estatuto de determinados aspectos de los derechos fundamentales es posible ${ }^{81}$. No podemos más que coincidir con esta opinión, sobre todo si se toma en cuenta que, en muchos de esos casos, estaríamos ante una elevación de rango de derechos que ya venían siendo regulados por el legislador autonómico ${ }^{82}$.

Debo advertir que en lo referente a derechos y principios constitucionales considero que, en efecto, la función que realizan los Estatutos es la de clarificación y desarrollo. En definitiva, entiendo que lo que buscan es «descubrir facetas de los derechos que no se encuentran explicitadas en el texto constitucional ${ }^{83}$. No comparto, por lo tanto, la opinión de quienes consideran que los nuevos Estatutos solo se limitan a reproducir los preceptos constitucionales sin otra ambición ${ }^{84}$. Y no lo hago porque esa postura carecería de sentido, ya que para hacer un viaje tan corto no sería preciso pertrecharse con tan grandes alforjas.

Y por último, aunque no por ello menos importante, las declaraciones de derechos también han venido a reconocer nuevos derechos. Al hablar de nuevos derechos nos estamos refiriendo a derechos que no encuentran una correlación ni una referencia en la Constitución, aunque sí la tienen en declaraciones internacionales de derechos. Es decir, no incluimos derechos que cuyo origen puede encontrarse, sin tener que acudir a retorcidas interpretaciones, en derechos constitucionalmente reconocidos. Un ejemplo de un derecho que, en mi opinión, no sería nuevo sería el derecho a vivir con dignidad la propia muerte que viene a ser una de las facetas del derecho a la vida ${ }^{85}$. Por lo tanto, en este punto discrepo de la postura defendida por APARICIO Y BARCELO quienes consideran que, aun cuando pudiera encontrarse relación con un derecho constitucional, son derechos de nuevo cuño. Su justificación descansa en que se trataría de «una nueva categoría de normas iusestatutarias con rango y garantías propias» ${ }^{86}$.

Pero lo cierto es que tal afirmación solo sería aplicable para los supuestos en que los derechos no encontraran referencia en preceptos constitucionales. En los demás casos se estaría produciendo una congelación del alcance de los preceptos constitucionales negándoles la

${ }^{81}$ C. ROSADO VILLAVERDE, La regulación Estatutaria..., op. cit, p. 79.

${ }^{82}$ Este es uno de los puntos sobre los que giró la controversia en torno a la capacidad de los Estatutos para regular derechos y es que recuérdese que fue criticado por una parte de la doctrina el que se quisiera impedir al colegislador estatuyente lo que puede el legislador autonómico.

${ }^{83}$ F. LÓPEZ MENUDO, "Los derechos sociales..., op. cit., p. 137.

84 Es el caso GARCÍA ROCA quién además de poner de manifiesto esa reproducción la desaconseja. En J. GARCÍA ROCA,"El riesgo de generalización de las asimetrías en las reformas estatutarias", en VV.AA (L. ORTEGA, ed.), La reforma del Estado autonómico, Centro de Estudios Políticos y Constitucionales, Madrid, 2005, p. 105.

${ }^{85}$ Así lo entiende el TC, que lo entiende como: «una manifestación del derecho a la vida digna y con el mismo alcance que para ese concepto puede deducirse de los arts. $10.1 \mathrm{y}$ 15 CE», STC 31/2010, FJ. 19.

${ }^{86}$ M. A. APARICIO PÉREZ y M. BARCELÓ I SERRAMELERA, "Los derechos públicos..., op. cit., p. 33. 
capacidad de adaptarse a las nuevas necesidades que la evolución de los tiempos propicia. Acogerse a otra interpretación, esto es, considerarlos derechos nuevos, vendría a suponer que los derechos constitucionales existentes no pueden otorgar protección jurídica a nuevas realidades, lo que significaría que la labor de interpretación de los derechos que puede realizar el TC quedaría seriamente cercenada ${ }^{87}$. Una interpretación de ese calado, llevada al extremo, supondría la necesidad de tener que acudir a procedimientos de reforma constitucional de un modo mucho más asiduo en aras de mantener lo más actualizada posible la declaración de derechos constitucional.

Es por las razones enunciadas que, al hablar de nuevos derechos nos referimos solo a aquellos que difícilmente podrían relacionarse con ningún precepto constitucional. Sirva como ejemplo más destacado, el derecho a una buena administración ${ }^{88}$ que, no teniendo una referencia directa en la Constitución, sí viene reconocido en el Carta de los Derechos Fundamentales de la Unión Europea ${ }^{89}$. Sin embargo, debemos apuntar que este tipo de derechos han sido formulados por el legislador autonómico de un modo tal que, si nos atenemos a la interpretación hecha por el TC, debemos considerarlos como mandatos y orientaciones al legislador y no como derechos subjetivos.

Siendo esta la situación de partida y, por así decirlo, la intención del estatuyente al proclamar esas declaraciones de derechos, no lo es menos que la realidad con que nos encontramos al analizar la naturaleza de los preceptos jurídicos que deberían llevar a efecto dichos propósitos no es tan ambiciosa. Como se ha referido cuando se ha tratado en el epígrafe anterior la naturaleza jurídica de los principios, nos encontramos con que muchos de los enunciados como derechos en los Estatutos no son tales, sino que su naturaleza es la propia de los principios. Basta con recordar la consideración que, para la STC 247/2007, merecían los derechos estatutarios, reducidos a orientaciones al legislador (dejando a salvo los derechos institucionales, en los que sí se admitía que pudieran ser derechos subjetivos). Si esta fuera la situación, lo cierto es que no tendríamos mucho más que analizar en lo tocante a la naturaleza de los derechos estatutarios. Sin embargo, con la STC 31/2010, aunque sigue la línea de la anterior, se abre la puerta a considerar que los Estatutos contienen derechos subjetivos, pues admite la posibilidad de que los contengan y, a la vez, desaparece la mención a que se circunscriban a los derechos institucionales como únicos derechos subjetivos posibles.

Por lo tanto, la sentencia $31 / 2010$ propicia que sea constitucionalmente posible afirmar que en las declaraciones de derechos estatutarias se regulan auténticos derechos subjetivos. Pero, más allá de lo que el TC señale como posible, lo cierto es que para que podamos decir

\footnotetext{
${ }^{87}$ Algo que no concuerda con nuestra realidad en la que incluso se han reconocido por vía interpretativa el derecho a la protección de datos o derechos relacionados nuevas tecnologías.

88 Artículos 12, 30 y 31 de los Estatutos de Castilla y León, Cataluña y Andalucía, respectivamente.

${ }^{89}$ Artículo 41.
} 
que los Estatutos contienen derechos subjetivos estos han de contar con las características que identifican a preceptos de tal naturaleza. Qué quiero decir con esto, que al final será el propio precepto el que, con su formulación, con las facultades que otorga, permita definirlo como derecho subjetivo, más allá del nomen iuris que le haya dado el estatuyente. De ahí que debamos analizar cada artículo, sin apriorismos, pues si bien es cierto que, con carácter general, el TC es reacio a reconocer la existencia de derechos subjetivos en los Estatutos, en tanto no la ha negado por completo, significa que hay preceptos que, si su formulación lo propicia, pueden tener esa naturaleza. A la identificación de esos preceptos dedicaremos las próximas líneas.

Para la tarea de determinación de la naturaleza de los preceptos estatutarios como derechos subjetivos tomaremos en consideración su formulación y grado de concreción. Con ello se busca identificar aquellos preceptos en los que «se especifican con absoluta claridad todos los elementos propios del derecho (su titular, su contenido, su objeto y el sujeto pasivo u obligado) que, de esta forma, se hace exigible jurisdiccionalmente de acuerdo con el artículo 53.3 CE (y con el propio Estatuto) y sin que, en absoluto, su cumplimiento quede sometido a condición suspensiva alguna» ${ }^{90}$. De reunir esas características estaríamos ante auténticos derechos subjetivos.

Como hemos señalado, las declaraciones de derechos contienen, en algunos casos, especificaciones de preceptos constitucionales. Desde un punto de vista operativo puede resultar conveniente, en la búsqueda de derechos subjetivos, partir de aquellos derechos estatutarios que son concreción de derechos constitucionales. En estos casos, y sin dar por segura su condición de derechos subjetivos, sí es cierto de que hay un alto porcentaje de posibilidades de encontrarnos ante preceptos que tengan dicha naturaleza.

Si se asume, y ya hemos señalado la razonabilidad de tal premisa, que hay aspectos de los derechos constitucionales que sí pueden ser desarrollados en vía estatutaria, no resulta extraño pensar que con esa concreción se esté formulando un auténtico derecho subjetivo. Esto será así, sobre todo, en los casos en que supone llevar a nivel estatutario lo que, desarrollado por el legislador autonómico, era considerado como derecho subjetivo. Una interpretación diferente a esta resultaría difícil de justificar, pues sería incongruente que el mismo precepto cambiara su naturaleza solo por pasar a estar regulado en otra fuente normativa, más cuando dicha norma tiene mayor jerarquía y lo formula como derecho.

Un supuesto que sirve para ilustrar lo que aquí se viene afirmando sería el artículo 21.5 del Estatuto de Autonomía de Andalucía, cuyo contenido encaja a la perfección en el propio de un derecho subjetivo en tanto que «Se garantiza la gratuidad de los libros de texto en la enseñanza obligatoria en los centros sostenidos con fondos públicos. La

90 M. A. APARICIO PÉREZ y M. BARCELÓ I SERRAMELERA, "Los derechos públicos..., op. cit., pp. 29 y 30. 
ley podrá hacer extensivo este derecho a otros niveles educativos». Como puede verse se trata de precepto en el que se recoge un derecho subjetivo pues el objeto (gratuidad de los libros de texto), y los destinatarios (estudiantes de los centros sostenidos con fondos públicos) quedan perfectamente definidos.

Se ha incorporado la segunda parte del precepto desde «la ley podrá...» para que sirva de contrapunto con la clase de regulación que caracteriza a un principio, en el que no hay un destinatario determinado ni un contenido definido. Creo que precisamente esa contraposición entre la gratuidad de los libros en determinados niveles de enseñanza frente a otros, en los que se queda a la espera de lo que el legislador autonómico determine, permite comprender, mejor de lo que con palabras pueda expresar, el nivel de certeza que caracteriza a un derecho subjetivo y cómo se distingue de un principio. De ahí que este artículo sea un ejemplo paradigmático de lo que los Estatutos han venido a configurar en sus declaraciones de derechos, pues contiene tanto un derecho subjetivo como un principio.

Sin embargo, no solo en supuestos en los en los que el Estatuto desarrolla derechos constitucionales podemos identificar derechos subjetivos. Al contrario, este sería un caso menor, pues la mayoría de los derechos estatutarios lo que buscaban era, como se ha dicho, elevar a la categoría de derechos lo que hasta ese momento eran principios. Con esta operación se hacía realidad, por vía de reforma estatutaria, lo que apuntó LÓPEZ MENUDO, que «cualquier legislador [en este caso sería el estatuyente] podría convertir en genuinos derechos subjetivos todos y cada uno de los "derechos sociales" que se citan en ese Cap. III [de la CE] - en la medida en que ello sea técnicamente posible- con lo cual habría logrado ejecutar óptimamente ese desiderátum constitucional [en referencia al desarrollo del estado social del artículo $1.1 \mathrm{CE}]^{91}$. Esa puntualización, «en la medida de lo posible», cobra pleno sentido en el caso de los derechos estatutarios pues el estatuyente viene limitado en su actuación a sus propias competencias y al respeto a la legislación estatal de base que pueda existir sobre la materia. Y, a pesar de ello, aun le resulta posible positivizar algunos derechos subjetivos cuyo origen radica en previsiones del Capítulo III de la CE.

La referida operación supone una elevación del nivel de protección de dichas materias y enriquece el acervo de derechos de los ciudadanos de esa CA. De hecho, es tal la relevancia de esta cuestión que fue una de las razones que impulsó los procesos de reforma emprendidos en la primera década del siglo XXI. Tomando estas notas en consideración, solo resta encontrar entre las declaraciones de derechos algunos que, teniendo su origen en principios rectores constitucionales, hayan elevado su nivel de protección al punto de poder considerar, sin género de dudas, que nos encontramos ante derechos subjetivos.

En ese sentido, una de las materias en las que más claramente se aprecia que se ha dado un paso adelante es en el ámbito sanitario, no con

${ }^{91}$ F. LÓPEZ MENUDO, "Los derechos sociales..., op. cit., p. 162. 
carácter general (lo que sería imposible teniendo en cuenta que se trata de una competencia compartida) pero sí en determinados aspectos del mismo, que se han pasado a configurar como derechos subjetivos. Sirvan como ejemplo los artículos 22.2 y 23 de los Estatutos de Autonomía de Andalucía y Cataluña respectivamente. En ambos casos se concretan algunas facultades de las que dispondrán los pacientes y usuarios, v. gr., el derecho a la confidencialidad de los datos médicos o el acceso al historial clínico. En estos casos, por vía estatutaria, se lleva a efecto la premisa contenida en la última parte del apartado 2 del artículo $43 \mathrm{CE}$, en la que se remite a la ley la concreción de derechos y deberes.

Un supuesto diferente, fuera del ámbito sanitario, lo encontramos en el artículo 13.4 del Estatuto de Castilla y León, en él se reconoce el derecho a un acceso gratuito al Servicio Público de Empleo para los ciudadanos de esa CA. Como puede constatarse, se trata de un precepto en el que tanto el objeto como los destinatarios están completamente acotados, por lo que estamos de un derecho subjetivo en toda su magnitud.

Sin embargo, debe señalarse que en la mayoría de preceptos no encontramos un grado de detalle tan amplio, lo que lleva a que no podamos considerarlos como derechos. Pero, no por ello debemos desconocer que han sido formulados por el estatuyente como derechos y que éste les ha rodeado, en algunos casos, de un sistema de garantías. A pesar de este último matiz, a la hora de calificar su naturaleza, y tomando en consideración las consecuencias jurídicas que implican, debemos inclinarnos por considerarlos más próximos a los principios que a los derechos subjetivos ( $y$ más con la interpretación que de los mismos hace el TC).

Pero, aun considerándolos principios, lo son de un modo peculiar. En ese sentido entiendo acertada la interpretación ofrecida por CABELLOS ESPIÉRREZ cuando señala que se ha introducido «un tertium genus formado por derechos estatutarios que son normas de principio, distintos, por tanto, de los principios rectores» ${ }^{92}$. Pues, como apuntan ALVAREZ CONDE y TUR ALSINA, "los derechos estatutarios que entrañan mandatos son también derechos, y que pueden operar como pautas prescriptivas, no solo directivas, para el ejercicio de las competencias" ${ }^{\prime 93}$. Y las consecuencias de tal opción legislativa se verán reflejadas en la exigibilidad de su contenido, aspecto que se desarrollará en la segunda parte de este trabajo.

\section{CONCLUSIÓN}

Las Comunidades Autónomas han pasado a ocupar un papel protagonista en la evolución y ampliación de los derechos como

\footnotetext{
92 M. A. CABELLOS ESPIÉRREZ, "Derechos y garantías jurisdiccionales en la sentencia sobre el Estatuto de Autonomía de Cataluña", Revista Catalana de Dret Public, Especial Sentencia sobre el Estatuto, No Extra 1, 2010, p. 160.

93 E. ÁlVAREZ CONDE y R. TUR AUSINA, Las consecuencias jurídicas de la sentencia 31/2010, de 28 de junio del Tribunal Constitucional sobre el Estatuto de Cataluña. La sentencia de la perfecta libertad, Aranzadi, Navarra, 2010, p.180.
} 
consecuencia de las reformas de sus Estatutos y la introducción en estos de Cartas de derechos. En este sentido, se puede llegar a cuestionar si existe algún impedimento jurídico para que los Estatutos de Autonomía proclamen derechos. A esta primera pregunta debe responderse, de un modo afirmativo, en tanto que no parece existir razón jurídica alguna que imposibilite a las normas de cabecera de las Comunidades Autónomas positivizar Cartas de derechos. Pueden hacerlo pero, eso sí, con dos importantísimas limitaciones que van a condicionar notablemente el alcance que las proclamaciones de derechos autonómicas pueden tener. De una parte, no pueden vulnerar la reserva de Ley Orgánica de los derechos fundamentales $y$, de otra, han de circunscribirse a su ámbito competencial. Si cumplen estos requisitos, los Estatutos pueden (si el legislador estatuyente lo estima oportuno) reconocer derechos.

Cuestión diferente será la naturaleza de esos derechos. Para responder a esta segunda pregunta debe atenderse a la formulación y al grado de certeza de los mismos. Tomando esas condiciones como guía en el estudio de las proclamaciones de derechos estatutarias puede concluirse que:

1. No puede hacerse un pronunciamiento general acerca de la naturaleza de los las cartas de derechos autonómicas sino que resulta necesario analizar cada derecho individualmente atendiendo a su formulación y grado de determinación. En definitiva no hay categorías cerradas respecto de las cuales pueda afirmarse con certeza que tienen una determinada naturaleza, pues en las declaraciones de derechos autonómicas conviven preceptos de naturaleza diversa.

2. A pesar de que no pueda atribuirse con carácter general una naturaleza específica a las declaraciones de derechos estatutarias, no es menos cierto que en los Estatutos predominan, de manera abrumadora, los mandatos y orientaciones al legislador.

3. El nomen iuris con el que aparecen proclamados los preceptos estatutarios no siempre va a coincidir con la naturaleza de los mismos. Si bien puede orientar el análisis de su naturaleza no debe ser el criterio único para determinarla.

4. En las cartas de derechos autonómicas hay configurados auténticos derechos subjetivos, aunque son muy pocos los preceptos a los que puede atribuírseles tal naturaleza.

5. A pesar de la escasez de derechos subjetivos, las declaraciones de derechos autonómicas han enriquecido el patrimonio jurídico de los ciudadanos, en tanto que la presencia de los derechos en los Estatutos de Autonomía les proporciona un nuevo estatus jurídico, además de suponer un impulso al desarrollo del Estado social.

\section{BIBLIOGRAFÍA}

M. J. AGUDO-ZAMORA, "Derecho a la vivienda y reformas estatutarias", Anuario da Facultade de Dereito da Universidade da Coruña, núm. 14, 2010, pp. 163-184.

M. A. AGUDO ZAMORA, "La efectiva constitucionalidad de la regulación de derechos estatutarios en la STC 31/2010", Teoría y Realidad Constitucional, No 27, 2011, pp. 461-480. 
E. AJA FERNÁNDEZ y P. PÉREZ TREMPS, "Tribunal Constitucional y organización territorial del Estado Autonómico", en VV.AA (E. ESPÍN TEMPLADO y F. DÍAZ REVORIO, coords.), La Justicia Constitucional en el Estado democrático, Cortes de Castilla-La Mancha/Tirant lo Blanch, Valencia, 2000.

E. AJA FERNÁNDEZ, Estado Autonómico y reforma federal, Alianza editorial Madrid, 2014.

E. ÁLVAREZ CONDE y R. TUR AUSINA, Las consecuencias jurídicas de la sentencia 31/2010, de 28 de junio del Tribunal Constitucional sobre el Estatuto de Cataluña. La sentencia de la perfecta libertad, Aranzadi, Navarra, 2010.

M. A. APARICIO PÉREZ y M. BARCELÓ I SERRAMELERA, "Los derechos públicos estatutarios", en VV.AA (M. A. APARCIO PÉREZ, ed.), Derechos y principios rectores en los Estatutos de Autonomía, Atelier, Barcelona, 2008.

M. ARAGÓN REYES, "¿Estado jurisdiccional autonómico?", Revista Vasca de Administración Pública, No 16, septiembre-diciembre, 1986, pp. 712.

M. ARAGÓN REYES, Estudios de Derecho Constitucional, Centro de Estudios Políticos y Constitucionales, Madrid, 2013.

P. BIGLINO CAMPOS, "La reforma de los Estatutos de Autonomía: un problema que se desplaza, otro que se agudiza y otros por resolver", Corts: Anuario de derecho parlamentario, No 25, 2011, pp. 19-35.

P. BIGLINO CAMPOS, "Los espejismos de la tabla de derechos" en Derechos, deberes y principios en el nuevo Estatuto de Autonomía de Cataluña, Centro de Estudios Políticos y Constitucionales, Madrid, 2006.

F. CAAMAÑO, "Sí, pueden (Declaraciones de derechos y Estatutos de Autonomía)", Revista Española Derecho Constitucional, No 79, eneroabril, 2007, pp. 33-46.

M. A. CABELLOS ESPIÉRREZ, "Derechos y garantías jurisdiccionales en la sentencia sobre el Estatuto de Autonomía de Cataluña", Revista Catalana de Dret Public, Especial Sentencia sobre el Estatuto, No Extra 1, 2010, pp. 155-161.

R. CANOSA USERA, "La declaración de derechos en los nuevos Estatutos de Autonomía", Teoría y Realidad Constitucional, No 20, 2007, pp. 59115.

M. CARRILlO, "La declaración de derechos en el nuevo Estatuto de Autonomía de Cataluña: expresión de autogobierno y límite a los poderes públicos", en Derechos, deberes y principios en el nuevo Estatuto de Autonomía de Cataluña, Centro de Estudios Políticos y Constitucionales, Madrid, 2006.

J. L. CASCAJO CASTRO, "Observaciones sobre la denominada función constitucional de los Estatutos de Autonomía", Teoría y Realidad Constitucional, núm. 23, 2009, pp. 133-177. 
P. CRUZ VILLALÓN, La curiosidad del jurista persa, y otros estudios sobre la Constitución, Centro de Estudios Políticos y Constitucionales, $2^{a}$ Edición, Madrid, 2006.

L. M. DÍEZ-PICAZO, "¿Pueden los estatutos de autonomía declarar derechos, deberes y principios?", Revista Española de Derecho Constitucional, No 78, septiembre-diciembre, 2006, pp. 63-75.

E. Expósito Gómez, "Declaraciones estatutarias ¿de derechos? Un análisis a la luz de las SSTC 247/2007 y 31/2010", Teoría y Realidad Constitucional, No 27, 2011, pp. 481-502.

E. EXPÓSITO GÓMEZ, "Derecho y garantías", Revista Catalana de Dret Públic, Especial Sentencia sobre el Estatuto, No Extra 1, 2010, pp. 168-172.

V. FERRERES COMELLA, "Derechos, deberes y principios en el nuevo Estatuto de Autonomía de Cataluña", en Derechos, deberes y principios en el nuevo Estatuto de Autonomía de Cataluña, Centro de Estudios Políticos y Constitucionales, Madrid, 2006.

J. GARCÍA ROCA, "El riesgo de generalización de las asimetrías en las reformas estatutarias", en VV.AA (L. ORTEGA, ed.), La reforma del Estado autonómico, Centro de Estudios Políticos y Constitucionales, Madrid, 2005.

J. GARCÍA TORRES, "Los derechos estatutarios en la propuesta catalana de reforma", en El Estado autonómico. Actas de las XI Jornadas de la Asociación de Letrados del Tribunal Constitucional, Centro de Estudios Políticos y Constitucionales, Madrid, 2006.

F. LÓPEZ MENUDO, "Los derechos sociales en los Estatutos de Autonomía", Administración de Andalucía. Revista andaluza de Administración Pública, No 73, 2009, pp. 71-190.

T. QUADRA-SALCEDO JANINI, "EI régimen jurídico de los derechos sociales estatutarios. Reflexiones tras la STC 247/2007, de 12 de diciembre", Revista General de Derecho Constitucional, No 5, 2008, pp. 1-48.

G. ROBLES MORCHÓN, Teoría del derecho: fundamentos de teoría comunicacional del derecho, Civitas, Madrid, 2010.

C. ROSADO VILLAVERDE, La regulación estatutaria de los derechos y libertades, Dykinson, Madrid, 2012.

S. A. ROURA GÓMEZ, Federalismo y Justicia constitucional en la Constitución española de 1978, Biblioteca Nueva, Madrid, 2003.

J. RUIPÉREZ ALAMILLO, La Constitución del Estado de las Autonomías, Biblioteca Nueva Madrid, 2003.

J. A. SANTAMARÍA PASTOR, Fundamentos de Derecho Administrativo, Editorial Centro de Estudios Ramón Areces, Madrid, 1988.

C. VIVER I PI SUNYER, "L' Estatut de 2006", Activitat Parlamentaria, No 10,2006, pp. $34-58$. 